\title{
A Matemática Crítica Como Caminho Para a Promoção da Educação Financeira no Ensino Médio
}

\section{Critical Mathematics as a Path to the Promotion of Financial Education in High School}

\author{
Lucas Athadeu Silva Batista; Vera Lúcia de Oliveira Freitas Ruas ${ }^{\mathrm{b}}$; Shirley Patrícia Nogueira de Castro e Almeida \\ Josué Antunes de Macêdo ${ }^{\mathrm{a}, \mathrm{c}}$; Edson Crisostomo*a
}

\author{
${ }^{a}$ Universidade Estadual de Montes Claros, Programa de Pós-Graduação Stricto Sensu em Educação. MG, Brasil.

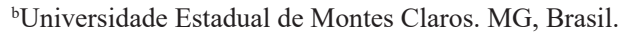 \\ 'Instituto Federal do Norte de Minas Gerais. MG, Brasil. \\ *E-mail: edsoncrisostomo@yahoo.es.
}

\begin{abstract}
Resumo
No Brasil, apesar da existência da Estratégia Nacional de Educação Financeira (ENEF), a Educação Financeira ainda não chegou até a maioria das escolas do País e muitos dos professores desconhecem o assunto e/ou a forma como realizar sua transposição didática. Nesse sentido, este artigo objetiva compreender a tessitura dialógica entre a Educação Financeira (EF) e a Educação Matemática Crítica (EMC) no Ensino Médio. A metodologia utilizada é qualitativa com enfoque bibliográfico. A análise terá como ponto de partida reflexões à luz da Base Nacional Comum Curricular (BNCC) e da legislação sobre EF vigente. Neste estudo se apresentam três contextos investigativos, quais sejam: (i) Referência à Matemática Pura, (ii) Referência a uma semirrealidade, e (iii) Referência à vida real, buscando assim problematizar a Educação Financeira, no âmbito escolar, a partir dos Ambientes de Aprendizagem e seu papel na promoção da emancipação dos alunos. São analisados e discutidos três trabalhos, nos quais se verificou a urgência de ressignificar a prática pedagógica do professor de Matemática para que utilize ferramentas teórico-práticas apropriadas em suas aulas, para que os estudantes tenham conhecimentos para construir uma vida financeira saudável. Portanto, os resultados dão indícios da importância da articulação da Educação Matemática Crítica à Educação Financeira para que seja feita a transposição didática dos conceitos tratados, em sala de aula, garantido sua utilização na vida cotidiana.
\end{abstract}

Palavras-chave: Educação Matemática. BNCC. Sociedade de Consumo. Emancipação.

\begin{abstract}
In Brazil, despite the existence of the National Strategy for Financial Education (ENEF), Financial Education has not reached most schools yet in the country and many of the teachers are unaware of the subject and / or how to carry out their didactic transposition. In this sense, this article aims to understand the dialogical composition between Financial Education (EF) and Critical Mathematical Education (EMC) in High School. The methodology used is qualitative with a bibliographic focus. The analysis will have as a starting point reflections in the light of the National Common Curricular Base (BNCC) and the current EF legislation. This study presents three investigative contexts, namely (i) Reference to Pure Mathematics, (ii) Reference to a semi-reality, and (iii) Reference to real life, thus seeking to problematize Financial Education in the school environment from the Learning and its role in promoting the student's emancipation. Three papers are analyzed and discussed, and there was an urgent need to re-signify the Mathematics teacher's pedagogical practice so that he or she can provide the theoretical and practical tools appropriate in his or her classes so that students have the knowledge to build a healthy financial life. Therefore, the results herein provide evidence of the importance of the articulation of Critical Mathematical Education to Financial Education so that the didactic transposition of the concepts treated in the classroom is carried out, guaranteeing its use in everyday life.
\end{abstract}

Keywords: Mathematical Education. BNCC. Consumer society. Emancipation.

\section{Introdução}

Na Sociedade de Consumo em que se vive, fomentada pelo Capitalismo e pela Globalização, o trabalho com a Educação Financeira no âmbito escolar tem se constituído, nas últimas décadas, foco de pesquisas na área de Educação Matemática, consequência da urgência de discussão que o tema move. Conforme aponta Bauman (1999), os consumidores deste tipo de sociedade estão sempre em movimento constante de procurar, buscar, não encontrar ainda não é sinônimo de malestar, mas promessa de bem-aventurança, talvez, a própria bem-aventurança. Neste eterno devir existe uma tendência para o consumismo impulsivo, desorientado, inconsequente e irrefletido, geralmente, para suprir lacunas e vazios emocionais, sentimentos típicos desta época, o que ocasiona, na maioria das vezes, em endividamento da população comprometendo a economia do país.

A temática Educação Financeira obteve notoriedade no cenário político global com a crise econômica mundial, em 2008, em que organizações internacionais, como a Organização para a Cooperação e Desenvolvimento Econômico (OCDE) ${ }^{1}$ compreendeu a importância de divulgar este assunto.

1 OCDE é uma organização internacional criada em 1960, que trabalha em parceria com Governos de vários países para construir políticas que promovam prosperidade, igualdade, oportunidade e bem-estar para todos. Esta entidade estabelece padrões internacionais na busca de soluções baseadas em evidências para inúmeros desafios sociais, econômicos e ambientais, desde a melhoria do desempenho econômico até a criação de empregos em uma determinada nação. 
Em uma das ações realizadas por esta organização se verificou, por meio de enquetes, o baixo nível de alfabetização financeira da população de países membros constatando a necessidade de estabelecer recomendações sobre os princípios e as boas práticas de educação e a conscientização financeira, que deveriam ser repassados aos indivíduos (OCDE, 2005)

Apesar de sua relevância, o conhecimento advindo desta área ainda é superficial por parte da população, conforme indica a pesquisa apontada no site oficial $^{2}$ da Estratégia Nacional de Educação Financeira (ENEF) - política pública responsável pela disseminação do tema - mostrando que, no Brasil, a Educação Financeira ainda não chegou à maioria das escolas do País e muitos professores desconhecem o assunto e/ou a forma de como realizar sua transposição didática. Nesse sentido, tem-se buscado medidas que favoreçam a expansão desse tema, principalmente, no âmbito escolar, acreditando em seu potencial multiplicador.

Além de programas de formação propostos por parceria entre iniciativas privadas e estatais, a Base Nacional Comum Curricular - BNCC (BRASIL, 2018) propõe sua abordagem como tema transversal, devendo ser abordada, de forma atrelada, a outras disciplinas. Sendo uma temática de relevância social, e possuindo relação com os conteúdos da Matemática, torna-se um ambiente propício para desenvolvimento de habilidades matemáticas, que permitam aos alunos uma atuação crítica e reflexiva, conforme prevê a Educação Matemática Crítica, em circunstâncias reais que envolvam a lida com o dinheiro.

Por se constituir em uma demanda antiga, o debate sobre esta temática que ora se apresenta aos leitores, se fundamenta no compromisso da escola com a cidadania conforme propõe a Lei de Diretrizes e Bases da Educação Nacional - LDBEN $n^{\circ}$ 9394/96 (BRASIL, 1996), no artigo 3º, inciso XI sobre a necessidade de: "[...] vinculação entre a educação escolar, o trabalho e as práticas sociais" e será problematizado como mencionado anteriormente, a partir das conexões entre Educação Financeira e Educação Matemática Crítica, assuntos de extrema complexidade, mas condizentes com as necessidades educacionais deste momento histórico, que exige dos indivíduos o uso consciente do dinheiro e a organização adequada das finanças pessoais.

O estudo bibliográfico tem enfoque da pesquisa qualitativa, que de acordo com Creswell (2007) é aquela em que o investigador utiliza como base para discussão as perspectivas sociais, reivindicatórias, participativas e colaborativas com foco em um destes aspectos ou na articulação entre esses.

A trajetória metodológica se inicia com a retomada histórica da Educação Financeira no Brasil e a legislação que trata da temática, discutirá a proposta da BNCC inserindo-a como Tema Transversal e a urgência de sua abordagem, de forma interdisciplinar, definição de termos e conceitos da
Educação Matemática Crítica e, por fim, a análise de estudos que preconizam os Ambientes de Aprendizagem propostos por Skovsmose (2000) como sendo essenciais para o processo de emancipação dos alunos do Ensino Médio.

Posto isto, este trabalho terá como objetivo geral compreender a tessitura dialógica entre a Educação Financeira (EF) e a Educação Matemática Crítica (EMC) no Ensino Médio. Como objetivo específico, propõe-se discutir a Educação Financeira e a sua inserção no processo de ensino e aprendizagem no Ensino Médio, à luz da Educação Matemática Crítica como estratégia emancipatória. Buscarse-á responder ao seguinte questionamento: de que maneira se evidencia a articulação entre Educação Financeira, Base Nacional Comum Curricular e a Educação Matemática Crítica para o Ensino Médio?

Nesse sentido, esse trabalho foi organizado em três seções com essa introdução. Na próxima seção se aborda a metodologia, a temática Educação Financeira e Educação Matemática Crítica, respectivamente, que sustentam as discussões deste artigo e, por último, são analisadas três pesquisas nas quais os autores Silva e Selva (2017), Melo e Pessoa (2019), Lovatti, Rosetti Junior e Oliveira (2015) discorrem sobre EMC nos processos de ensino e aprendizagem, envolvendo Educação Financeira nas aulas do Ensino Médio. Por fim, encerra-se s com as considerações finais.

\section{Desenvolvimento}

\subsection{Metodologia}

A pesquisa se pautou por uma abordagem qualitativa com pesquisa documental, a partir da Base Nacional Comum Curricular (BNCC) e da legislação sobre Educação Financeira. Foi adotado, também, o enfoque bibliográfico, por meio do qual se buscou, nas teorias sobre a Educação Matemática Crítica e Educação Financeira, uma base conceitual para analisar três contextos investigativos, quais sejam: Referência à Matemática Pura; Referência a uma semirrealidade, e Referência à vida real. A partir disso foi possível problematizar a Educação Financeira, no âmbito escolar, considerando os Ambientes de Aprendizagem e seu papel na promoção da emancipação dos alunos, bem como se constatou a necessidade de ressignificação da prática do professor de Matemática, ensejando sua mediação e intervenção para que os estudantes se apropriem de conhecimentos para a construção de uma vida financeira saudável.

\subsection{Educação Financeira}

No Brasil, em conformidade com as orientações da OCDE, o tema emergiu como política de Estado com a publicação do Decreto $n^{\circ} 7.397$, de 22 dezembro de 2010 (BRASIL, 2010), que instituiu a Estratégia Nacional de Educação Financeira (ENEF), integrando entidades públicas e 
privadas interessadas em promover a Educação Financeira no país. Esse decreto foi revogado e substituído pelo Decreto $\mathrm{n}^{\circ}$ 10.393, de 9 de junho de 2020 (BRASIL, 2020), que instituiu a nova Estratégia Nacional de Educação Financeira - ENEF e o Fórum Brasileiro de Educação Financeira - FBEF.

A consolidação da ENEF acontece por meio do Comitê Nacional de Educação Financeira (CONEF), instância responsável pela direção, supervisão e pelo fomento da ENEF, formada por sete órgãos e entidades de Governo e quatro organizações da sociedade civil e do Grupo de Apoio Pedagógico (GAP), colegiado do qual o Ministério da Educação é membro permanente, de caráter deliberativo e consultivo que auxilia o Comitê na inspeção, revisão e ratificação de documentos com cunho didático/pedagógico dos Programas Educação Financeira nas Escolas do Ensino Fundamental e Médio, sendo estes operados pela Associação de Educação Financeira do Brasil - AEF-Brasil (BRASIL, 2020).

De acordo com a $\operatorname{OCDE}$ (2005, p.5), a Educação Financeira é:

[...] o processo pelo qual consumidores/investidores financeiros aprimoram sua compreensão sobre produtos, conceitos e riscos financeiros e, por meio de informação, instrução e/ou aconselhamento objetivo, desenvolvem as habilidades e a confiança para se tornarem mais conscientes de riscos e oportunidades financeiras, a fazer escolhas informadas, a saber onde buscar ajuda, e a tomar outras medidas efetivas para melhorar seu bem-estar financeiro.

Trata-se, portanto, de um conjunto de habilidades que permite ao indivíduo tomar decisões conscientes e responsáveis perante situações que envolvem a lida com o dinheiro. Corroborando com o exposto acima, Campos, Teixeira e Coutinho (2015) afirmam que a Educação Financeira se alinha com a ideia de educação para a cidadania ao permitir o desenvolvimento de uma postura mais ativa por parte dos indivíduos nas questões econômicas, podendo promover melhoria na qualidade de vida.

De acordo com Savoia (2007), nas últimas décadas, em função de mudanças nas relações econômicas e sociopolíticas mundiais provocadas pela globalização, desenvolvimento tecnológico e a expansão das políticas neoliberais, surge, por parte do indivíduo, a necessidade de uma postura mais ativa na gestão das finanças pessoais.

Tal postura se remete à aquisição de habilidades que permitam a leitura crítica e reflexiva perante circunstâncias que envolvam a lida com dinheiro para posterior tomada de atitude consciente e, em um cenário de instabilidade econômica, no qual a população tem sido forçada a conter despesas e assumir menos riscos com os gastos, assim, tais habilidades se tornam ainda mais necessárias.

Um dos caminhos para ampliar o alcance desta cultura é a abordagem da temática como tema transversal para ser trabalhada na Educação Básica, conforme a Deliberação $\mathrm{n}^{\circ}$ 19, de 16 de maio de 2017 que estabelece diretrizes para o
Programa Educação Financeira nas Escolas prevendo como mudança Epistemológica a atualização do documento de orientação em conformidade com a BNCC (BRASIL, 2018).

Neste viés, a BNCC do Ensino Médio propõe para o ensino de Matemática cinco competências e 45 habilidades, sendo que quatro das competências e sete das habilidades possuem relação com a Educação Financeira e/ou Matemática Financeira, buscando sempre uma aplicação dos conteúdos da Matemática em cenários do cotidiano, que envolvam, de alguma forma, a lida com questões financeiras e tomadas de decisão. Nesse sentido, se percebe que um caminho interessante para abordagem da temática seja com base nas ideias da Educação Matemática Crítica.

\subsection{Educação Matemática Crítica}

A Educação Matemática Crítica é um movimento que surgiu, no âmbito da Educação Matemática, na década de 1980, ocupando-se de suas questões políticas. Para Skovsmose (2014, 2015), a Educação Matemática Crítica não é um ramo ou subárea da Educação Matemática e nem se restringe ao desenvolvimento de métodos e técnicas pedagógicas, mas é uma perspectiva pela qual são analisados o caráter sociopolítico que a Educação Matemática pode desempenhar na sociedade, é uma expressão acerca das incertezas da Educação Matemática e da própria Matemática. $\mathrm{O}$ autor afirma que:

[...] a educação matemática crítica inclui o interesse pelo desenvolvimento da educação matemática como suporte da democracia, implicando que as micro-sociedades de salas de aulas de matemática devem também mostrar aspectos de democracia. A educação matemática crítica enfatiza que a matemática como tal não é somente um assunto a ser ensinado e aprendido (não importa se os processos de aprendizagem são organizados de acordo com uma abordagem construtivista ou socio-cultural). A Matemática em si é um tópico sobre o qual é preciso refletir (SKOVSMOSE, 2000, p. 67).

Nesse sentido, a Educação Matemática Crítica busca uma prática democrática no processo de ensino e aprendizagem, de modo que os alunos não sejam somente capazes de resolver exercícios matemáticos, mas tenham condições de refletir e agir criticamente, por meio da Matemática, em situações que a envolvem de alguma maneira. $\mathrm{O}$ fato de estar presente em debates da sociedade, sustentando decisões políticas, administrativas e estruturando recursos tecnológicos atribui à Matemática o caráter de poder, evidenciando o que Borba e Skovsmose (2015) consideram como Ideologia da Certeza e Poder Formatador da Matemática.

$\mathrm{O}$ primeiro diz respeito à neutralidade e ao poder de decisão definitiva conferidas a Matemática, expressas na sociedade por meio de frases como foi provado matematicamente, os números demonstram que, ou as equações asseguram que, entre outras, sustentando a ideia de que sua aplicação é cabível em qualquer situação e que os seus resultados são, impreterivelmente, melhores do que aqueles alcançados sem o seu uso. 
Enquanto o segundo se refere às estruturas de sociedade, que são organizadas a partir de arquétipos matemáticos, dessa forma, ao se tomar decisões a partir de modelos matemáticos se permite que essa molde a realidade, o que realça a necessidade da reflexão a partir dos seguintes aspectos: o que é feito por meio dessa modelagem?, que ações sociais e tecnológicas são realizadas?, quais são as implicações sociais, politicas e ambientais dessas ações?

Corroborando com essa ideia, Araújo (2007) traz um exemplo sobre a necessidade do pensamento crítico em relação às circunstâncias de que a Matemática, enquanto Ciência presente no cotidiano, ao mesmo tempo que fornece subsídios para o desenvolvimento da sociedade, pode por meio destes causar danos. Como exemplo, Araújo (2007) fala sobre o Índice de Desenvolvimento Humano (IDH):

[...] apoiando-se em modelos matemáticos, é associado um número entre 0 e 1 a cada cidade ou localidade. A partir dele, o governo, por exemplo, decide como realizar a distribuição de verbas visando um determinado objetivo. Uma cidade, apenas pelo fato de ter associado a ela um IDH próximo de 1 , pode deixar de receber uma verba que resolveria alguns de seus problemas. Assim, os modelos matemáticos são utilizados para criar uma "situação real" que antes não existia. Evidencia-se, pois, o relevante papel da Matemática na construção da sociedade tecnológica. Podemos afirmar, então, que ela é corresponsável pelos conflitos e pela crise nela existentes (ARAÚJO, 2007, p.33).

Tais constatações se tornaram evidentes, a partir de trabalhos de Modelagem Matemática desenvolvidos com alunos da graduação de Geografia e Matemática, nos quais foi possível perceber o uso de fórmulas e modelos matemáticos, de forma inconsciente, sem saber o porquê e quais as consequências advindas de tais práticas.

A partir do exposto anteriormente, Borba e Skovsmose (2015) não pretendem desvalorizar a Matemática, enquanto instrumento útil na sociedade, pelo contrário, ressaltam a sua importância, mas demonstram que essa está sujeita às interferências e conveniências humanas, daí a importância da reflexão sobre o seu uso. Em consonância com estes autores, Miranda et al. (2012, p.13) afirmam que a Educação Matemática Crítica "[...] objetiva despertar questionamentos, estimular a criticidade de a provocar no educando maior participação social".

Tais objetivos estão presentes nos documentos que regem e orientam a inserção da Educação Financeira nas escolas: “[...] formar para a cidadania, educar para consumir e poupar de modo ético, consciente e responsável" (ENEF, 2017, p. 1). De acordo com Campos, Teixeira e Coutinho (2015), a Educação Financeira se encontra com os objetivos da Educação Crítica, ao buscar inserir, no ambiente escolar, o confronto com problemas sociais consequentes da má administração das finanças pessoais, pretendendo modificar a realidade.

No contexto escolar, a Educação Financeira é proposta pela Base Nacional Comum Curricular (BNCC) (BRASIL, 2018) para ser abordada como tema transversal de forma integrada e entre as disciplinas nas quais seria possível abordála. Vinculada à Matemática, são esperados bons resultados, pois a Educação Financeira pode propiciar um ambiente de aplicação dos conteúdos matemáticos em situações da vida real, permitindo aos alunos uma formação de acordo com o que é previsto pelo currículo de Matemática e suas Tecnologias do Ensino Médio.

Em continuidade a essas aprendizagens, no Ensino Médio o foco é a construção de uma visão integrada da Matemática, aplicada à realidade, em diferentes contextos. Consequentemente, quando a realidade é a referência, é preciso levar em conta as vivências cotidianas dos estudantes do Ensino Médio - impactados de diferentes maneiras pelos avanços tecnológicos, pelas exigências do mercado de trabalho, pelos projetos de bem viver dos seus povos, pela potencialidade das mídias sociais, entre outros. Nesse contexto, destaca-se ainda a importância do recurso a tecnologias digitais e aplicativos tanto para a investigação matemática como para dar continuidade ao desenvolvimento do pensamento computacional, iniciado na etapa anterior. Diante dessas considerações, a área de Matemática e suas Tecnologias tem a responsabilidade de aproveitar todo o potencial já constituído por esses estudantes no Ensino Fundamental, para promover ações que ampliem o letramento matemático iniciado na etapa anterior. Isso significa que novos conhecimentos específicos devem estimular processos mais elaborados de reflexão e de abstração, que deem sustentação a modos de pensar que permitam aos estudantes formular e resolver problemas em diversos contextos com mais autonomia e recursos matemáticos(BRASIL, 2018, p.528-529).

Ao demonstrar a intenção de trabalhar a Matemática, a partir de situações do cotidiano dos estudantes, considerando suas condições socioeconômicas e permitindo o desenvolvimento das habilidades de reflexão e criticidade na tomada de decisões conscientes se percebe um ambiente favorável para exploração da Educação Financeira, no viés da EMC. Skvosmose (2000) afirma que aulas desenvolvidas em ambientes de investigação favorecem o desenvolvimento da materacia, que "não se refere apenas às habilidades matemáticas, mas também à competência de interpretar e agir numa situação social e política estruturada pela matemática" (SKVOSMOSE, 2000, p.67).

Skovsmose (2000) aponta dois padrões que, geralmente, são seguidos pelos professores nas aulas de Matemática: (i) o Paradigma do Exercício, e (ii) os Cenários para investigação. $\mathrm{O}$ primeiro traduz bem o modelo bancário de Educação, termo cunhado por Freire (2011), em que os estudantes recebem, passivamente, o conhecimento em forma de depósitos. Em sentido oposto, o segundo se relaciona a uma aula problematizadora, em que os alunos são convidados a investigação e, se aceitam este convite, terão a oportunidade de construir o conhecimento de forma coletiva. Um cenário para investigação se configura como aquele que solicita aos alunos formularem questões e procurarem explicações para as soluções destas atividades propostas, convertendo esta ação nesse ambiente de aprendizagem em um novo espaço, nos quais os alunos são responsáveis pelo processo (ALRØ; 
SKOVSMOSE, 2010).

Entretanto, Skovsmose (2000) atenta que o que irá diferenciar as duas práticas nas salas de aulas serão as posturas dos professores de Matemática perante os objetos de conhecimentos pautados nas seguintes referências com enfoque à Matemática Pura, à semirrealidade ou à realidade. O autor apresenta, conforme especificado, no Quadro 1, a combinação dos dois paradigmas com os três tipos de referências se consolidando no que intitula como Ambientes de Aprendizagem.

Quadro 1 - Ambientes de Aprendizagem

\begin{tabular}{|l|c|c|}
\hline & $\begin{array}{c}\text { Listas de } \\
\text { Exercícios }\end{array}$ & $\begin{array}{c}\text { Cenário } \\
\text { para } \\
\text { Investigação }\end{array}$ \\
\hline Referência à Matemática pura & $(1)$ & $(2)$ \\
\hline Referência a uma semirrealidade & $(3)$ & $(4)$ \\
\hline Referência à vida real & $(5)$ & $(6)$ \\
\hline
\end{tabular}

Fonte: Skovsmose (2000, p.8).

Na matriz do Quadro1, que deve ser utilizada como instrumento analítico, conforme especifica o autor, as atividades do ambiente (1) fazem menção à Matemática Pura e condizem com situações descontextualizadas de atos mecânicos de resolução de operações matemáticas. No cenário do tipo (2), verifica-se que, apesar de fazer referência à Matemática Pura, pode proporcionar aos alunos momentos de reflexões em relação aos desafios matemáticos apresentados nas abordagens em sala de aula.

No ambiente (3), a semirrealidade se constitui como processo de criação de situações hipotéticas, que se prestam a finalidade de apenas exemplificar a situação dada. O contexto (4) distingue-se do anterior, porque apesar de se basear também em semirrealidade, relaciona-se a cenários para investigação, mas como uma situação construída artificialmente com o único propósito de resolução da atividade. Sendo assim: “[...] o ensino da Matemática tradicional está muito associado à resolução de exercícios referentes à Matemática Pura ou a semirrealidade" (ALRØ, SKOVSMOSE, 2010, p.55).

Os ambientes (5) e (6) se configuram nas vertentes da EMC por fazerem referência à vida real e serem alicerçados no diálogo entre esta realidade social, política e econômica e a Matemática. No ambiente (5), os professores podem propor situações problemas que envolvam notícias retiradas dos meios de comunicação e no contexto (6), enquanto Cenários de Investigação, o trabalho com projetos com a abordagem interdisciplinar pode ser o diferencial com o convite aos alunos para construí-lo coletivamente e colocá-lo em prática.

Além disso, Skovsmose (2000) sustenta que a Educação Matemática deve se mover entre os diferentes paradigmas e lança uma sugestão aos professores da Educação Básica para se deslocar da referência à Matemática Pura para a referência à vida real como uma oportunidade de engajar os alunos em ação e reflexão na dimensão da EMC.

As discussões de Skovsmose $(2000,2015)$ e Alrø e
Skovsmose (2010) convergem para um dos principais pontos da EMC, que tem como destaque a proposta da pedagogia problematizadora e emancipadora de Freire (2011), no qual o autor propõe uma relação dialógico-dialética entre professores e alunos fundamentais para a democracia, em que prevalecem o diálogo, a troca de informações, a interação e a produção coletiva do conhecimento que deem significados reais para suas vidas.

\subsection{Tecendo comentários}

Nesta seção foram compiladas e discutidas três pesquisas em que os autores Silva e Selva (2017), Melo e Pessoa (2019), Lovatti, Rosetti Junior e Oliveira (2015) propõem-se a discutir à luz da EMC processos de ensino e aprendizagem significativos sobre a Educação Financeira, nas aulas do Ensino Médio, com a perspectiva de responder os anseios sobre a temática conduzindo a uma abordagem da pesquisa para a linha teórico-prática.

A seguir serão apresentados os resultados encontrados no estudo, no que diz respeito à averiguação nas pesquisas de práticas pedagógicas que possibilitam um processo de ensino e aprendizagem pautado na EMC e EF mais emancipadoras.

As análises dos dados apurados conduziram para a elaboração, apresentação e discussão da temática de forma mais concreta por meio de contextos investigativos, todos encaminhados sobre o viés dos Ambientes de Aprendizagem, em que se busca elucidar se as contribuições da Educação Financeira e a sua inserção no processo de ensino e aprendizagem à luz da EMC se constituindo estratégia emancipadora para jovens do Ensino Médio.

No Contexto 01, Silva e Selva (2017), em seu artigo, intitulado: Programa de Educação Financeira nas escolas - Ensino Médio: uma análise dos materiais na perspectiva da Educação Matemática Crítica objetivaram analisar as atividades propostas aos alunos no material didático elaborado pela Estratégia Nacional de Educação Financeira (ENEF), tendo o Ministério da Educação (MEC) como signatário, para o trabalho com Educação Financeira, em aulas do Ensino Médio, à luz da Educação Matemática Crítica, especialmente, em relação ao potencial do mesmo para desenvolver cenários para investigação.

As pesquisadoras Silva e Selva (2017) verificaram, a partir da análise dos livros dos alunos do Ensino Médio, elaborados pela ENEF em parceria com o MEC, para o Programa de Educação Financeira, apresentados em forma de situações didáticas, o nível alto de contextualização entre o cotidiano dos indivíduos, a Matemática em uma abordagem crítica e a Educação Financeira como pontos fortes da proposta.

Pode-se perceber, no Quadro 2, que "a maioria das questões propostas no material analisado podem desenvolver cenários para investigação (76), estando 32 situações na semirrealidade e 44 na realidade" (SILVA; SELVA, 2017, p.368). 
Quadro 2 - Ambiente de Aprendizagem distribuído por blocos

\begin{tabular}{|l|c|c|c|c|}
\hline \multicolumn{1}{|c|}{$\begin{array}{c}\text { Ambiente de } \\
\text { Aprendizagem }\end{array}$} & $\begin{array}{c}\text { Bloco } \\
\mathbf{1}\end{array}$ & $\begin{array}{c}\text { Bloco } \\
\mathbf{2}\end{array}$ & $\begin{array}{c}\text { Bloco } \\
\mathbf{3}\end{array}$ & Total \\
\hline $\begin{array}{l}\text { 4 (semirrealidade + cenário } \\
\text { para investigação) }\end{array}$ & 8 & 14 & 10 & 32 \\
\hline 5 (realidade + exercício) & 2 & 1 & 5 & 8 \\
\hline $\begin{array}{l}\text { 6 (realidade + cenário para } \\
\text { investigação) }\end{array}$ & 12 & 15 & 17 & 44 \\
\hline
\end{tabular}

Fonte: Dados da pesquisa.

Contudo, salientam que apesar de compreenderem que os materiais avaliados sejam importantes para um trabalho significativo com os alunos do Ensino Médio, esse não surtirá efeito sem um esforço efetivo por parte dos professores, que deverão sair da sua zona de conforto ao aportar nas práticas de exercícios e seguir para uma área que exigirá mais tempo e dedicação dos profissionais da educação tanto no processo ensino e aprendizagem, quer seja no planejamento ou na aplicação em sala de aula. Por fim, destacam que o diferencial realmente será a formação de professores para trabalhar Educação Financeira, a partir dos preceitos da Educação Matemática Crítica, propiciando um sujeito autônomo, crítico e ético em suas relações financeiras (SILVA; SELVA, 2017).

Os desfechos do estudo demonstraram que as atividades dos livros do aluno apresentam potencial para o desenvolvimento dos ambientes de aprendizagem com enfoque na realidade e cenários de investigação, aproximando a Matemática escolar, da vivenciada pelos alunos no cotidiano, colaborando para o desenvolvimento de práticas mais reflexivas para possíveis mudanças de postura em relação à Matemática e/ou Educação Financeira.

No contexto 02, Melo e Pessoa (2019) discorreram, no artigo: Educação Financeira no Ensino Médio: possibilidades, sendo este um recorte do estudo de mestrado, sobre a abordagem da Educação Financeira (EF) relacionada com a Matemática Financeira, a partir de um grupo de estudo com dois professores de Matemática no Ensino Médio.

Por meio da análise e discussão do resultado da aplicação de um minicurso aos professores investigados com atividades de potencial significativo e da observação de aulas nas turmas de $1^{\circ}$ ano, com duração média de duas horas cada aula, sendo utilizados para discussão os resultados do estudo da fundamentação teórica da EMC de Skovsmose (2000), para que os leitores compreendessem que a "EF trata-se de algo bem mais complexo, que envolve aspectos como: política, meio ambiente, psicologia, economia, entre outros" (MELO; PESSOA, 2019, p. 510).

Importante destacar que para os autores op cit., a interligação entre a realidade dos alunos e as atividades de EF é de suma importância, pois:

[...] apesar da ampla presença de situações financeiras na sociedade, ainda é necessário que a EF oferecida obtenha um caráter crítico, em que os sujeitos não sejam levados pela influência da mídia, que estimula o consumo, incentivando a aquisição de bens móveis e imóveis, construindo verdadeiras 'armadilhas' financeiras. Destacamos ainda a importância de tomarmos como base as preocupações da EMC para o trabalho com a EF para que tenhamos cada vez mais jovens e adolescentes com uma formação crítica no que tange às situações financeiras e que isso reflita em mudanças na estrutura familiar, escolar e social (MELO; PESSOA, 2019, p. 499).

A proposta de estudo destes pesquisadores op cit. contemplava o momento de prática em sala de aula com a finalidade de discutir os pontos altos de destaque das atividades dos professores, sendo que o trabalho com material da realidade, na Prática 1 foram utilizados cupons fiscais para análise dos impostos que são pagos em compras de supermercados e na Prática 2 se fez uso de panfletos de lojas da cidade para exemplificar algumas estratégias utilizadas pelas lojas para influenciar na decisão de pagamentos à vista ou a prazo.

Verifica-se com a conclusão da pesquisa que não existe uma forma única de trabalho para a EF, no Ensino Médio, a necessidade do trabalho sistemático com dados reais nas discussões, em sala de aula, de forma ampla e subjetiva, deve ser incentivada e que a abordagem da temática deve acontecer além do campo matemático com enfoque na formação de sujeitos críticos.

No contexto 03, Lovatti, Rosetti Junior e Oliveira (2015) organizaram algumas sequências de atividades como produto do Mestrado Profissional em Ciências e Matemática com o trabalho intitulado: A Educação Matemática Crítica na Educação Financeira com o propósito de instruir sobre a importância de ensinar o conteúdo de Matemática Financeira de uma forma diferenciada no Ensino Médio com foco na EMC, atividades que se aproximassem de um Cenário de Investigação.

Lovatti, Rosetti Junior e Oliveira (2015) destacam, ainda, que as seis situações problema apresentadas no guia são indicadas para o trabalho com alunos do Ensino Médio e envolvem o conceito de juros compostos, taxa de juros, o valor do dinheiro no tempo, investimentos, empréstimos e condições de pagamento. Afirmam que as atividades elencadas têm a finalidade de conduzir os alunos a uma participação ativa no processo ensino e aprendizagem, formulando perguntas e levantando questões, desfazendo-se das práticas mecânicas de simples repetidores de técnicas de exercícios e conduzidos a competência crítica de temáticas voltadas para finanças.

Sendo assim, apontam que alunos do Ensino Médio:

[...] devem estar preparados para resolver situações-problema que lhes são impostas no dia a dia, identificando o que lhes seria mais favorável em transações comerciais e financeiras, seja na tomada de decisão quanto a compras à vista ou a prazo, seja com relação às taxas de juros praticadas pelo mercado, dentre outras situações (LOVATTI; ROSETTI JUNIOR; OLIVEIRA, 2015, p.24).

Os autores demonstraram com o estudo que a Educação Financeira com enfoque na EMC traz imbuída a necessidade de despertar nos alunos a capacidade de optar em situações financeiras por uma decisão acertada, conduzindo-os a 
compreensão de que esta pode melhorar ou prejudicar a qualidade de vida das pessoas. Com a discussão teóricoprática justificam a urgência do trabalho com competências relacionadas aos direitos e deveres de cada indivíduo e devem exercer sua cidadania nos aspectos relacionados com as finanças pessoais de forma consciente.

\section{Conclusão}

Em geral, verificou-se que a Educação Financeira, no âmbito escolar do Ensino Médio, é uma temática ainda pouco explorada, mas que causa interesse em várias áreas do conhecimento, principalmente, após a promulgação da BNCC que propôs o status de Tema Transversal à temática e lhe conferiu a necessidade da abordagem interdisciplinar por ser uma área complexa demais para ser discutida somente pela Matemática.

Apurou-se, ainda, com o estudo que o educador não deve persistir na visão ultrapassada de uma Matemática como pura, completa, absoluta e inatingível pelos alunos do Ensino Médio como a abordagem do Paradigma dos Exercícios, por exemplo. Este profissional deve se incumbir de convidar os alunos para participarem de atividades de EF exploradas, de forma crítica, criativa, ética e emancipadora para que eles possam ser protagonistas do conhecimento quanto ao uso consciente do dinheiro, tendo nos Cenários de Investigação o aporte para refletir sobre as inúmeras possibilidades que a Matemática pode proporcionar.

Enfim, certos de que este assunto não se esgota nesta reflexão, pelo contrário, espera-se sensibilizar os professores de Matemática do Ensino Médio, que têm papel preponderante na construção de uma sociedade justa e democrática, para que percebam que o ponto central da EF elencado pela BNCC, com aportes na EMC, consiste no nível de formação crítica, materacia e na relação que os professores conseguem estabelecer com os alunos ao conferir a estes sujeitos as ferramentas apropriadas para que tenham uma vida financeira saudável, somente assim acontecerá, efetivamente, a sua verdadeira emancipação.

\section{Referências}

ALRØ, H.; SKOVSMOSE, O. Diálogo e aprendizagem em educação matemática. Belo Horizonte: Autêntica, 2010.

ARAÚJO, J.L. Educação matemática crítica na formação de pós-graduandos em educação matemática. In. ARAÚJO, J.L. Educação matemática crítica: reflexões e diálogos. Belo Horizonte: Fino Traço, 2007. p.25-38.

BAUMAN, Z. Globalização: as consequências humanas. Rio de Janeiro: Jorge Zahar, 1999.

BORBA, M.C.; SKOVSMOSE, O. A ideologia da certeza em educação matemática. In.: BORBA, M.C.; SKOVSMOSE, O. Educação matemática crítica: a questão da democracia. Tradução Abigail Lins; Jussara de Loiola Araújo. Campinas: Papirus, 2015. p. 127-148.

BRASIL. Lei no 9394, de 20 dez. 1996. Estabelece as diretrizes e bases da educação nacional. Diário Oficial, Brasília, 23 dez. 1996.
BRASIL. Decreto n ${ }^{\circ} 7.397$, de 22 de dezembro de 2010. Estratégia Nacional de Educação Financeira. Brasília, DF, 2010. Disponível em http:/www.planalto.gov.br/ccivil_03/_Ato2007-2010/2010/ Decreto/D7397.htm. Acesso em: $30 \mathrm{dez} .2020$.

BRASIL. Base nacional comum curricular. Ministério da Educação, Secretaria de Educação Básica. Brasília, DF, 2018. Disponível em: http://basenacionalcomum.mec.gov.br/images/ BNCC_EI_EF_110518_versaofinal_site.pdf. Acesso em: 10 jan. 2021.

BRASIL. Decreto $\mathrm{n}^{\circ}$ 10.393, de 9 de junho de 2020. Institui a nova Estratégia Nacional de Educação Financeira -ENEF e o Fórum Brasileiro de Educação Financeira-FBEF. Diário Oficial da União, Brasília, DF, 10 jun. 2020. Seção 1, p. 2.

CAMPOS, C.R.; TEIXEIRA, J.; COUTINHO, C.Q.S. Reflexões sobre a educação financeira e suas interfaces com a educação matemática e a educação crítica. Educ. Matem. Pesq., v.17, n.3, p.556-577, 2015.

CRESWELL, J.W. Projeto de pesquisa: métodos qualitativo, quantitativo e misto. Porto Alegre: Artmed, 2007.

ENEF - Estratégia Nacional de Educação Financeira. Orientações para educação financeira nas escolas. Brasília, DF, 2017. Disponível em: https:/www.vidaedinheiro.gov.br/wp-content/ uploads/2017/04/Info-EscolasFinal.pdf. Acesso em: $30 \mathrm{dez}$. 2020 .

FREIRE, P. Pedagogia do oprimido. São Paulo: Paz e Terra, 2011.

LOVATTI, F.A.; ROSETTI JUNIOR, H.; OLIVEIRA, A.J. $A$ educação matemática crítica na educação financeira. Edifes Acadêmico. Vitória: Instituto Federal de Educação, Ciência e Tecnologia do Espírito Santos, 2015.

MELO, D.P.M.; PESSOA, C.A.S. Educação financeira no ensino médio: possibilidades. ReBECEM, v.3, n.2, p.488-513, 2019. doi: https://doi.org/10.33238/ReBECEM.2019.v.3.n.2.22536.

MIRANDA, C.T. et al. Educação matemática crítica: propostas de atividades de acadêmicos de licenciatura em matemática. Educere, v.12, n.1, p.7-36, 2012.

OCDE - Centro OCDE/CVM de Educação e Alfabetização Financeira para América Latina e o Caribe. Recomendação sobre os princípios e as boas práticas de educação e conscientização financeira. 2005. Disponível em: https:// www.oecd.org/daf/fin/financial-education/[PT] $\% 20$ Recomenda\%C3\%A7\%C3\%A3o\%20Princ\%C3\%ADpios $\% 20$ de $\% 20$ Educa $\%$ C $3 \%$ A $7 \%$ C $3 \%$ A30\%20Financeira $\% 202005 \% 20$. pdf. Acesso em: 6 jan. 2021.

SAVOIA, J.R.F.; SAITO, A.T.; SANTANA, F.A. Paradigmas da educação financeira no Brasil. Rev. Adm. Pública, v.41, n.6, p.1121-1141, 2007.

SILVA, I.T. Programa de educação financeira nas escolas de ensino médio: uma análise dos materiais propostos e sua relação com a matemática. Recife: Universidade Federal de Pernambuco, 2017.

SILVA, I.T.; SELVA, A.C.V. Programa de educação financeira nas escolas - ensino médio: uma análise dos materiais na perspectiva da educação matemática crítica. Rev. Paranaense Educ. Matem., v.6, n.12, p.350-370, 2017.

SKOVSMOSE, Ole. Cenários para investigação. Bolema, v.13, n.14, p. 66-91, 2000.

SKOVSMOSE, O. Educação matemática crítica: a questão da democracia. Campinas: Papirus, 2015.

SKOVSMOSE, O. Um convite a educação matemática crítica. Campinas: Papirus, 2014. 